\title{
Status Report on New Whole Waveform Discriminants and Preliminary Results (Deliverable \#12)
}

\author{
W.R. Walter
}

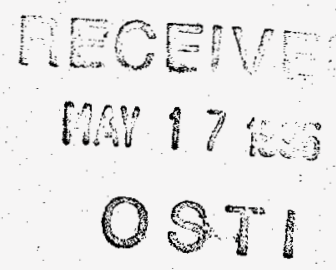

June 1, 1995

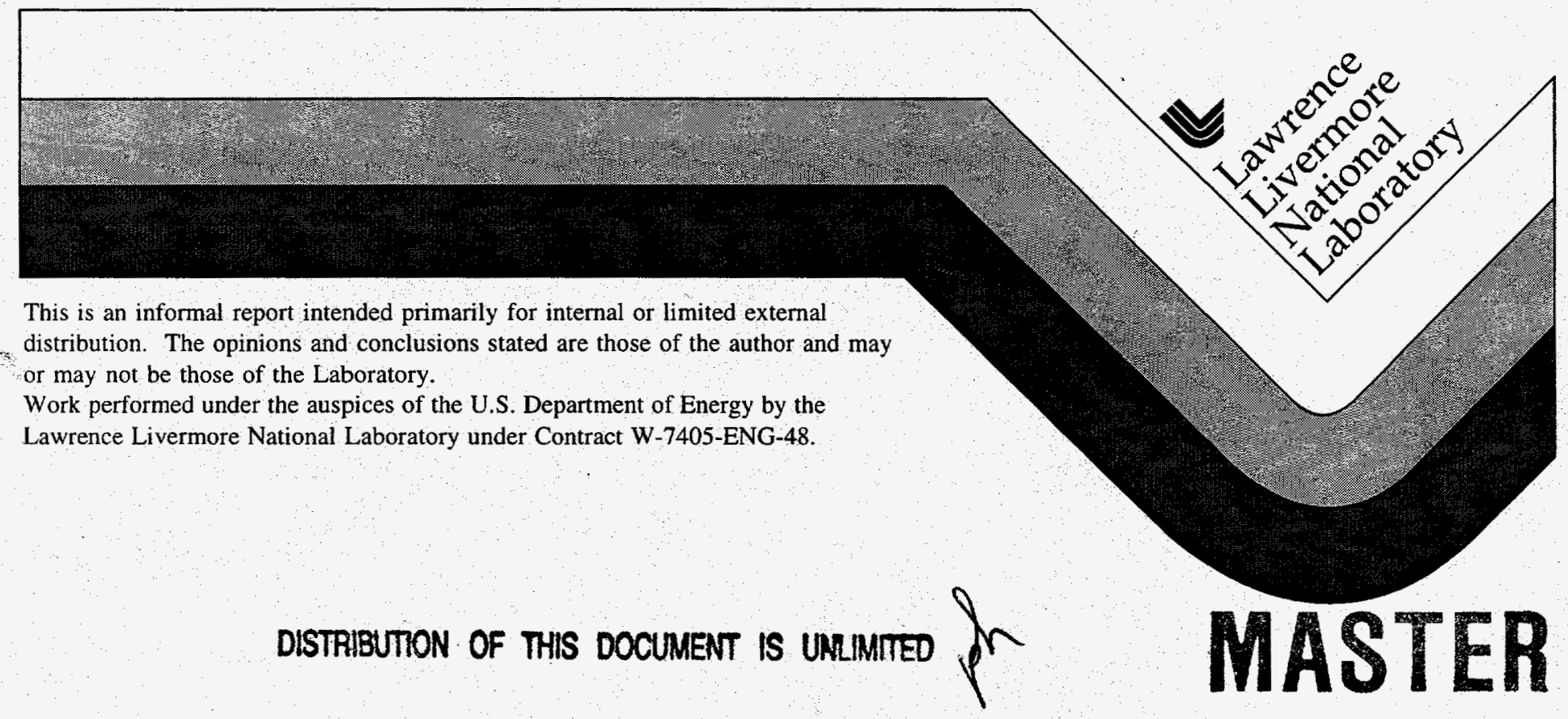




\section{DISCLAIMER}

This document was prepared as an account of work sponsored by an agency of the United States Government. Neither the United States Government nor the University of California nor any of their employees, makes any warranty, express or implied, or assumes any legal liability or responsibility for the accuracy, completeness, or usefulness of any information, apparatus, product, or process disclosed, or represents that its use would not infringe privately owned rights. Reference herein to any specific commercial product, process, or service by trade name, trademark, manufacturer, or otherwise, does not necessarily constitute or imply its endorsement, recommendation, or favoring by the United States Government or the University of California. The views and opinions of authors expressed herein do not necessarily state or reflect those of the United States Government or the University of California, and shall not be used for advertising or product endorsement purposes.

This report has been reproduced directly from the best available copy.

Available to DOE and DOE contractors from the Office of Scientific and Technical Information P.O. Box 62 , Oak Ridge, TN 37831

Prices available from (615) 576-8401, FTS 626-8401

Available to the public from the

National Technical Information Service

U.S. Department of Commerce

5285 Port Royal Rd.

Springfield, VA 22161 


\section{DISCLAMIER}

Portions of this document may be illegible in electronic image products. Images are produced from the best available original document. 


\title{
CTBTR\&D Program: LLNL Seismic Monitoring Project Task S4.3.4 - Devising New Waveform Discriminants
}

\author{
Status Report on New Whole Waveform Discriminants and \\ Preliminary Results \\ (Deliverable \#12) \\ William R. Walter \\ Lawrence Livermore National Laboratory \\ June 1, 1995
}

The Treaty Verification Program at Lawrence Livermore National Laboratory has made good progress during fiscal year 1995 on devising and testing whole seismic waveform modeling methods to identify seismic events using only a few stations. This research is carried out under the Comprehensive Test Ban Treaty Research and Development Program (CTBTR\&D) under task S4.3.4. For regions where the path is calibrated, this modeling can potentially identify and discriminate between clandestine underground nuclear events and other sources of seismic waves such as earthquakes and mine collapses. In regions where the path is not calibrated but is seismically active, we are investigating the use of moderate to large earthquakes to obtain the necessary path calibration. Our research has focused on improving whole waveform techniques for determining the source mechanism of moderate (magnitude greater than about 3.5) seismic events from a few three-component broadband sensors in regions where the paths are calibrated. Presently we are also using these waveform techniques in new regions to test and improve path calibrations as well as to identify events . As part of this work, we have applied these waveform techniques to events of high monitoring interest with excellent results. In this report we discuss fitting three main types of events, explosions, earthquakes and mine collapses.

In previous work we developed a new waveform modeling technique to estimate source parameters from entire regional seismograms recorded at as few as one station (Walter, 1993). This work built upon the efforts of many previous researchers who used portions of the regional seismogram to estimate source parameters (e.g. Patton, 1988; Fan and Wallace, 1991; Dreger and Helmberger, 
1991). An example of this modeling is shown in Figure 1. The top of the figure shows the three component ground displacement as a function of time at the LLNL broadband station KNB, Utah for the moderate sized Little Skull Mountain, NV earthquake. The broad band record contains energy over a large spectrum of frequencies and the resulting ground motion in at the top of Figure 1 is fairly complicated. However when we filter the seismograms at periods longer than about 10 seconds, the ground motion becomes fairly simple as shown in Figure 1b. At these longer periods it becomes possible to match the observed ground motions with synthetic seismograms calculated for fairly simple one dimensional regional earth models. At these longer periods we can ignore the finite dimensions and duration of most sources since these values are small compared to the wavelengths and periods used in the modeling. This allows us to do grid searches or inversions to find the best fitting mechanism which matches the data.

There are a variety of possible point source representations for observed seismic waves, and in this report we will concentrate on the three simplest, earthquakes, explosions and collapses. All these sources can be described in terms of the six independent elements of the symmetric nine element seismic moment tensor (e.g. Aki and Richards, 1980). Earthquakes occur when two blocks of the earth's crust slide past one another along a fault plane. This source can be represented as two symmetric couples. An example of the fit of synthetic seismograms to data using this type of mechanism is shown at the bottom of Figure 2. A spherically symmetric explosion source model would be represented by three equal outwardly directed couples in the $x, y$ and $z$ directions. An example of the type of fit that can be obtained with synthetic seismograms for this explosion source is shown in Figure 2a for the Nevada Test Site (NTS) explosion ATRISCO recorded at the LLNL station MNV, Nevada. Note that this record is dominated by the Rayleigh waves and that the Pnl and Love waves are rather small. A lack of Pnl and Love waves is characteristic of an non-earthquake source. While earthquake double couples can have Love wave nodes at particular azimuths, having at least two stations differing is azimuth can usually resolve this degeneracy.

Large collapses that generate seismic waves are less common than the other source types and there is less agreement on the appropriate seismic point source representation. Looking at a small subset of large magnitude collapses we have 
found that a tabular collapse mechanism represented by displacements only in the vertical or $\mathrm{z}$ direction does a good job of matching the data. This mechanism may be thought of as a closing tensile crack (e.g. Aki and Richards, 1980, p 52-53, Walter and Brune, 1993). This mechanism provides a very similar synthetic waveform to the point force collapse mechanism used by Taylor (1994) for the Gentry Mountain, Utah mine collapse. An example of our collapse mechanism fit is shown in Figure $2 \mathrm{~b}$ for the collapse of the cavity created by ATRISCO some twenty minutes after the explosion. We note that this mechanism differs from a pure implosion (the opposite of the explosion source) since the Mzz couple is larger in magnitude than the Mxx and Myy. We illustrate the difference in Figure 3 where we compare ATRISCO and its collapse. Note in Figure 3a the Rayleigh waves for the explosion and collapse are opposite phase from each other. We can match up the Rayleigh waves quite well by scaling the collapse by a negative mutiplicative factor as shown at the bottom of Figure 3 . Note that the Pnl waves do not match up, as would be expected if the collapse were a pure implosion or negative explosion. The change in the Pnl comes from Mzz>Mxx=Myy in the tabular collapse source.

We apply the waveform modeling technique to events of monitoring interest by performing a grid search over the three mechanisms described above for broadband data which has been filtered to frequency bands where the appropriate one dimension velocity is known. For example we used the method on the magnitude 5.2 event which occurred February 3, 1995 in Wyoming, injuring several people in an active mine. Although this event was initially reported as an earthquake by several people, we were able to show from waveform modeling that the seismic energy radiated by this event came from a collapse and not an earthquake source (Pechmann et al., 1995). An example of the fitting is shown for the station ELK in Figure 4. On the left it can be seen that while the collapse is consistent with the Rayleigh waves on the vertical component the explosion source is not. On the right hand side of Figure 4, the Love waves are small so we can rule out the earthquake mechanism shown here. However we cannot rule out other earthquake mechanisms which are near nodal at ELK. To definitely rule out an earthquake mechanism we need data from other azimuths. Figure 5 shows the data at four different stations is consistent with the collapse mechanism, confirming the collapse mechanism In addition we were able to gather ground truth data for this event from the mine company. 
Ground truth data and leveling data confirmed that a very large room and pillar section of the mine collapsed (Pechmann, et al., 1995).

We applied a very similar analysis to the January 5, 1995 event in the Ural Mountains region in Russia. This magnitude $\mathrm{mb}=4.7$ event was initially reported by TASS the Russian news agency as a "tectonic shock" but the press release also noted mine damage consistent with a collapse (pillar failure) and a subsequent explosion in the mine from the ignition of released methane. It remained unclear which of the sources was responsible for the observed seismic signal. We had one calibrated path to a broadband station for this event, the IRIS station ARU. Modeling at this station indicated the Rayleigh wave phase was consistent with a collapse and not an earthquake as shown in Figure 6. Examining other more distant stations (Figure 6), the lack of long period Love waves for other azimuths appears to confirm the collapse mechanism and rules out a large earthquake or double couple mechanism. Other evidence, including a $\mathrm{P} / \mathrm{Lg}$ ratio examination by Baumgardt (personal communication) and further reports of mine damage and past mine rockbursts in the area( P. G. Richards and A. Malovichko, personal communication) is also consistent with a collapse mechanism. We believe the majority of the seismic energy from this event came from a mine collapse.

We are in the process of testing the method in new regions of high interest to AFTAC and others in the monitoring community. Transporting this method to new regions requires careful path calibration first. We are using existing seismicity in other regions to perform this calibration. In conclusion we believe the waveform modeling technique can be a very powerful tool to resolve ambiguous seismic events that may be ambiguous from regional discriminant measurements such as phase and spectral ratios (e.g. Walter et al., 1995). Present seismic waveform techniques need the observation of intermediate period body and surface waves on carefully calibrated paths.

Acknowledgments. The study benefited from discussions with Howard Patton. 
References

Aki, K. and P. G. Richards, Quantitative Seismology, W. H. Freeman, New York, 1980.

Dreger, D. S., and D. V. Helmberger, Source parameters of the Sierra Madre earthquake from regional and local body waves, Geophys Res. Lett, 18, 2015-2018, 1991

Fan G. and T Wallace, The determination of source parameters for small earthquakes from a single very broadband seismic station, Geophys. Res. Lett., 18, 1385-1388, 1991.

Patton, H. J., Source models of the Harzer explosion from regional observation of fundamental-mode and higher-mode surface waves, Bull. Seism. Soc. Am., 78, 1133-1157, 1988.

Pechmann, J.C., W. R. Walter, S. J. Nava, and W. J. Arabasz, The February 3, 1995 Ml 5.1 seismic event in the trona mining district of southwestern Wyoming, Seism. Res. Lett. 66, 25-34, 1995.

Taylor, S. R., False alarms and mine seismicity: an example from the Gentry Mountain mining region, Utah, Bull. Seism. Soc. Am., 84, 350-358, 1994.

Walter, W. R. and J. N. Brune, Spectra of seismic radiation from a tensile crack, J. Geophys. Res., 98, 4449-4459, 1993.

Walter, W. R., Source parameters of the June 29, 1992 Little Skull Mountain earthquake from complete regional waveforms at a single station, Geophys. Res. Lett., 20, 403-406, 1993.

Walter, W. R., K. M. Mayeda and H. J. Patton, Phase and spectral ratio discrimination between NTS earthquakes and explosions part I: empirical observations, Bull. Seism. Soc. Am., 85, 1050-1067, 1995. 


\section{Source Parameters from Waveforms at a Single Station:}

The 6/29/92 Little Skull Mountain Earthquake at KNB

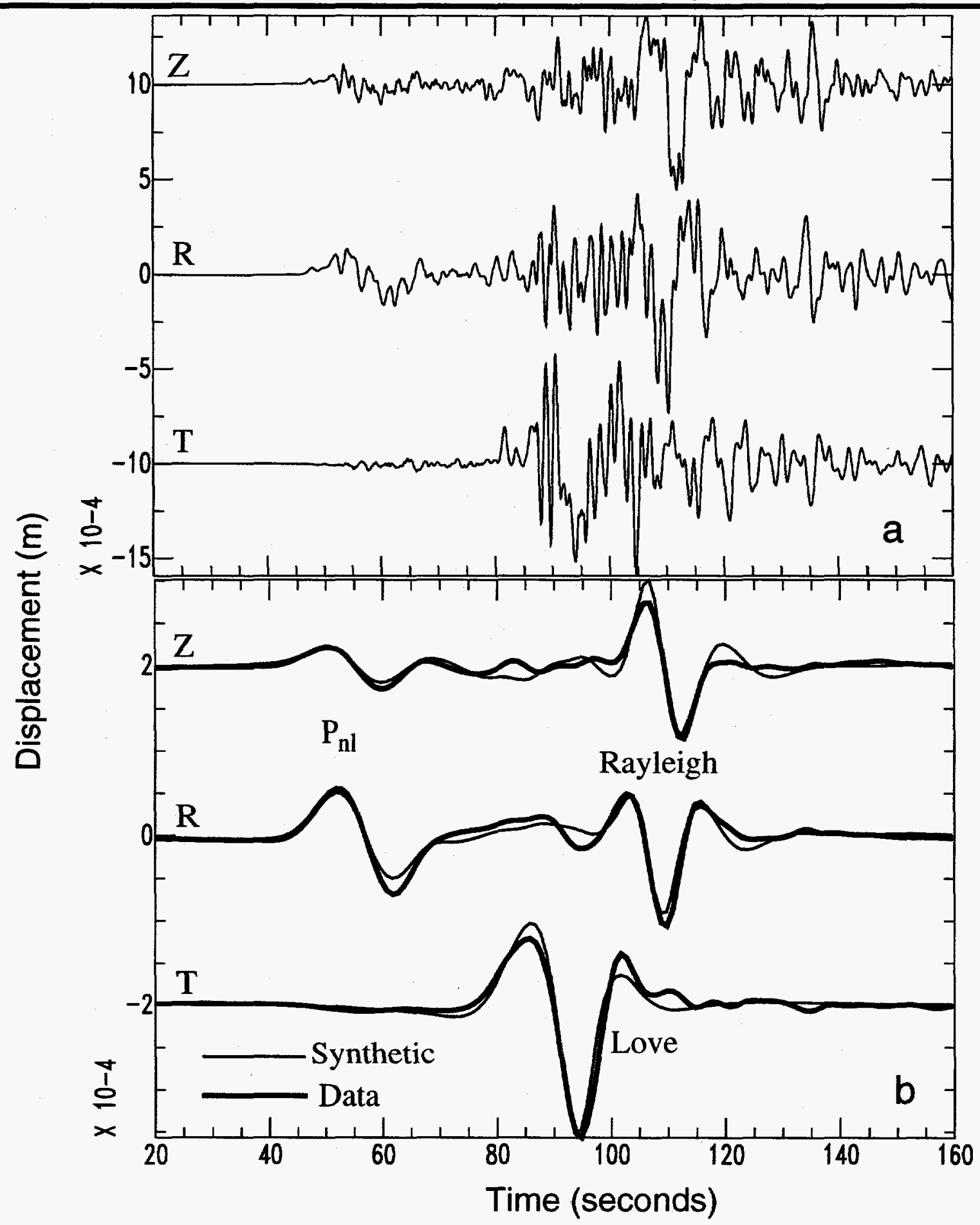

Fig. 1. An example of seismic waveform modeling at a single station to identify the source parameters. (a) Shows the three components of ground motion ( $\mathrm{Z}$ - vertical, $\mathrm{R}$ - Radial, $\mathrm{T}$ Transverse) recorded by a broadband seismometer at station KNB in Utah from the June 29, 1992 Little Skull Mtn., NV earthquake. (b) shows the same traces in black, much simplified after bandpass filtering between 50 and $15 \mathrm{~s}$ period. Note the good match to this long period data using 1-D synthetic seismograms for a normal earthquake shown in thin red lines. The long period body wave phase Pnl and the Rayleigh and Love surface waves are labeled. (after Walter, 1993, Figure 2) 


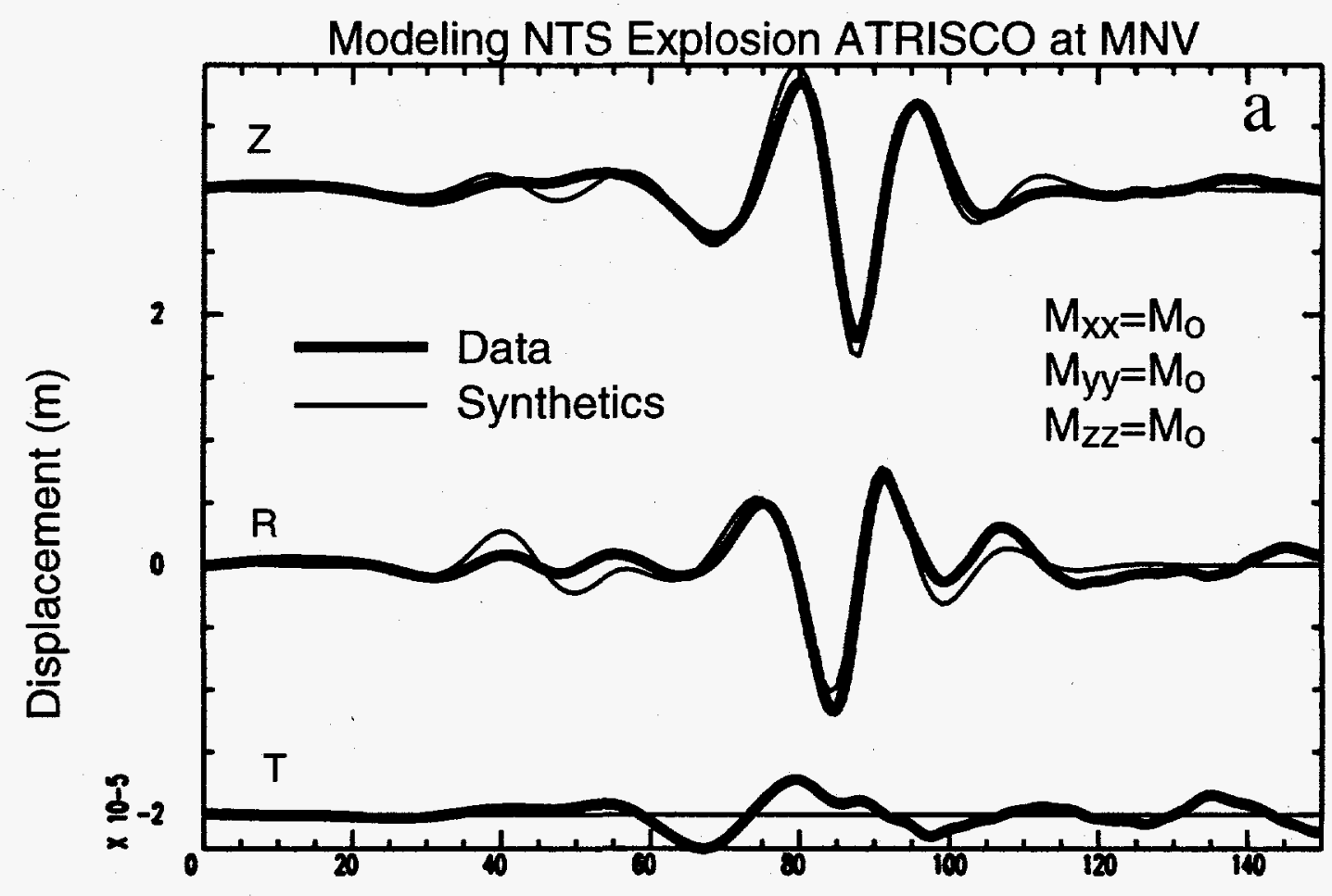

Modeling Collapse Following ATRISCO at MNV

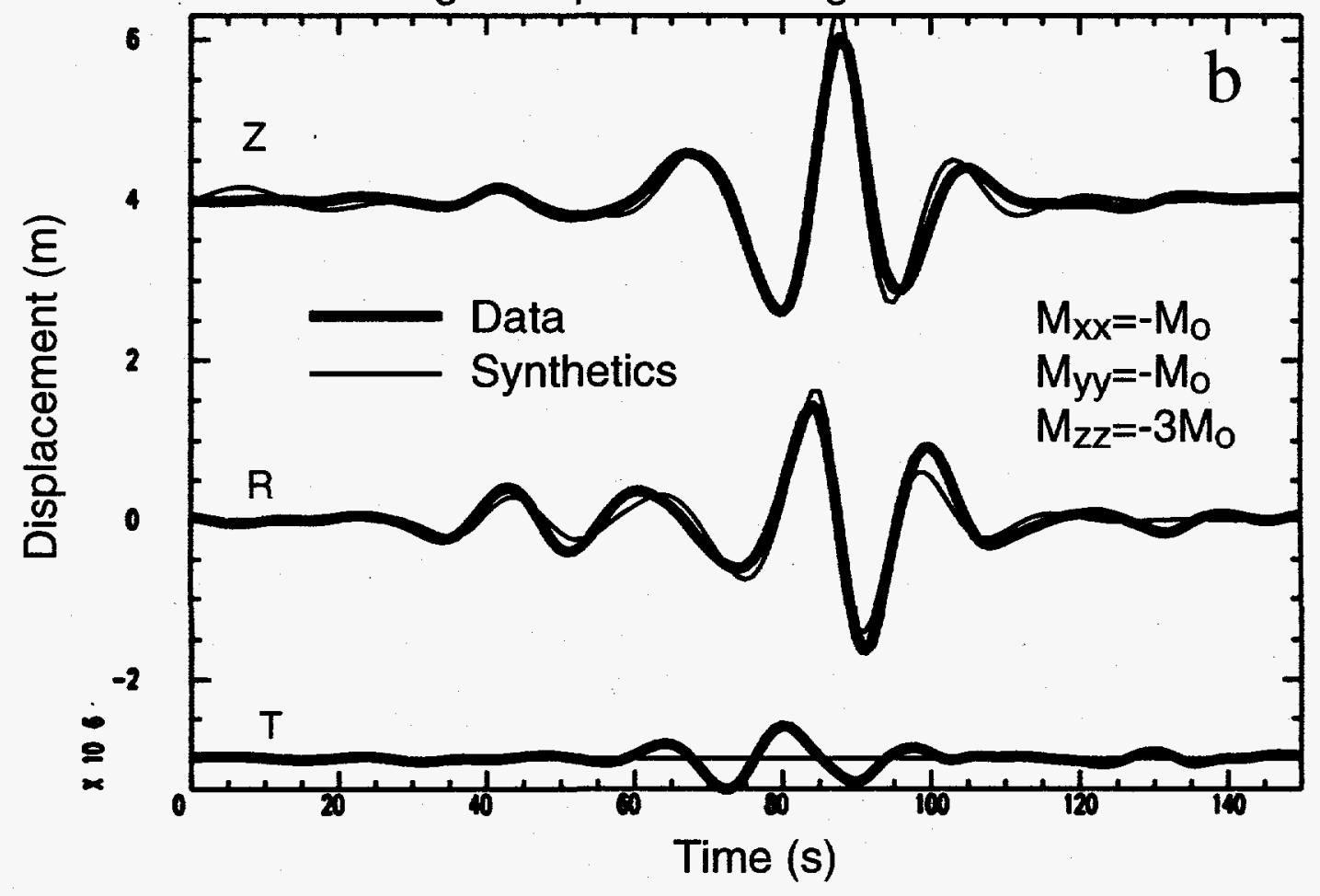

Fig. 2. Example of waveform modeling fits at the LLNL station MNV in the period band 50-15 s for an explosion and a collapse source. (a) Shows the fit of a pure explosion source to the NTS explosions ATRISCO recorded at MNV. (b) shows the fit of a pure collapse source to the ATRISCO-COLLAPSE recorded at MNV some twenty minutes after the shot. 


\section{Comparing ATRISCO and its Collapse at ELK}
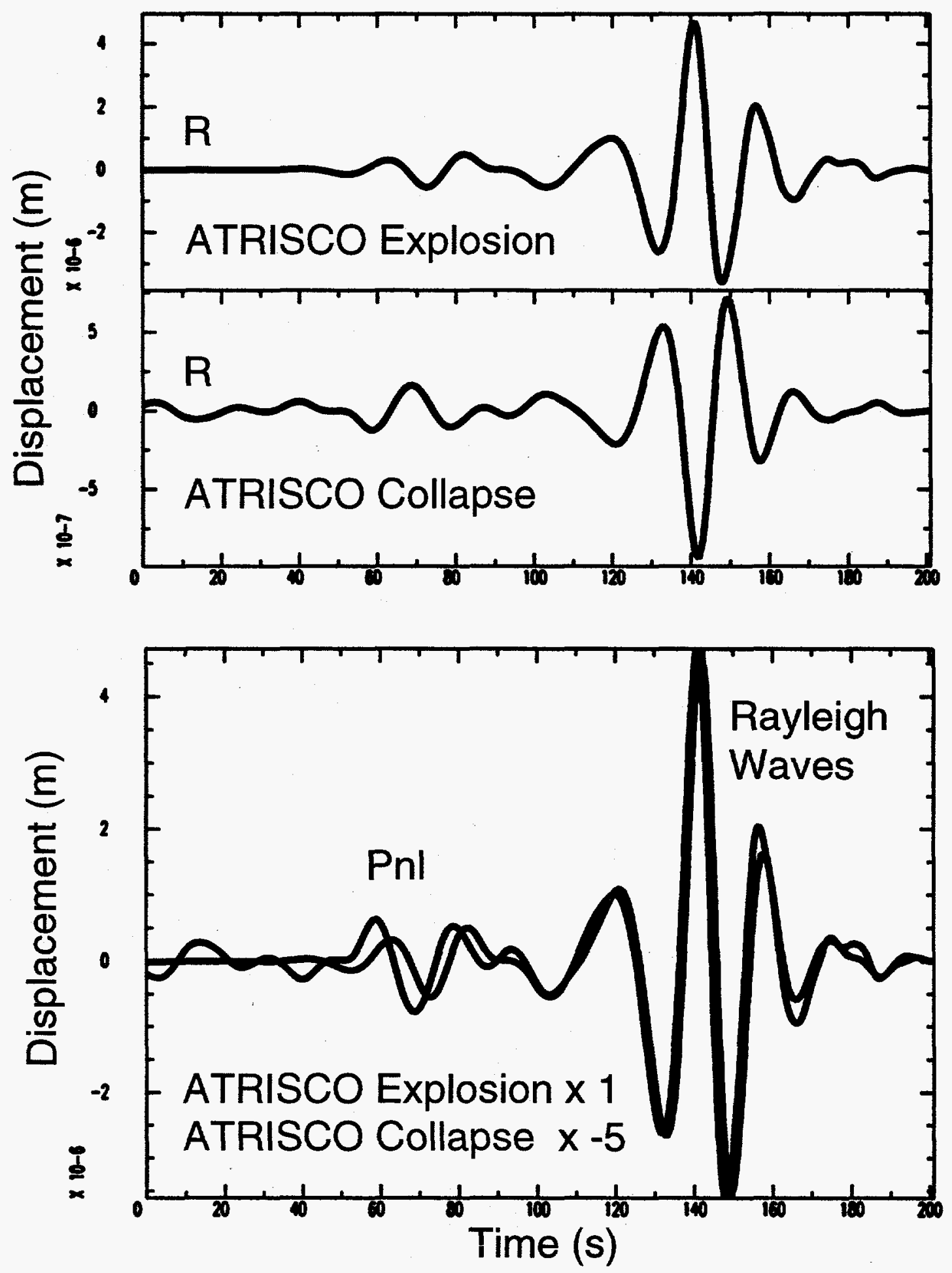

Fig. 3. A comparison of the ELK radial component long period (15-40 s) seismograms from the NTS explosion ATRISCO and its associated cavity collapse about twenty minutes later. (a) Note that the Rayleigh waves are out of phase for these two events. We can match the Rayleigh waves of the two events if we multiply the collapse trace by -5 as shown in (b). However the long period body wave phase Pnl does not match, indicating the collapse is not the opposite of an explosion, but more consistent with a tabular collapse mechanism as shown in Figure 2 b. 


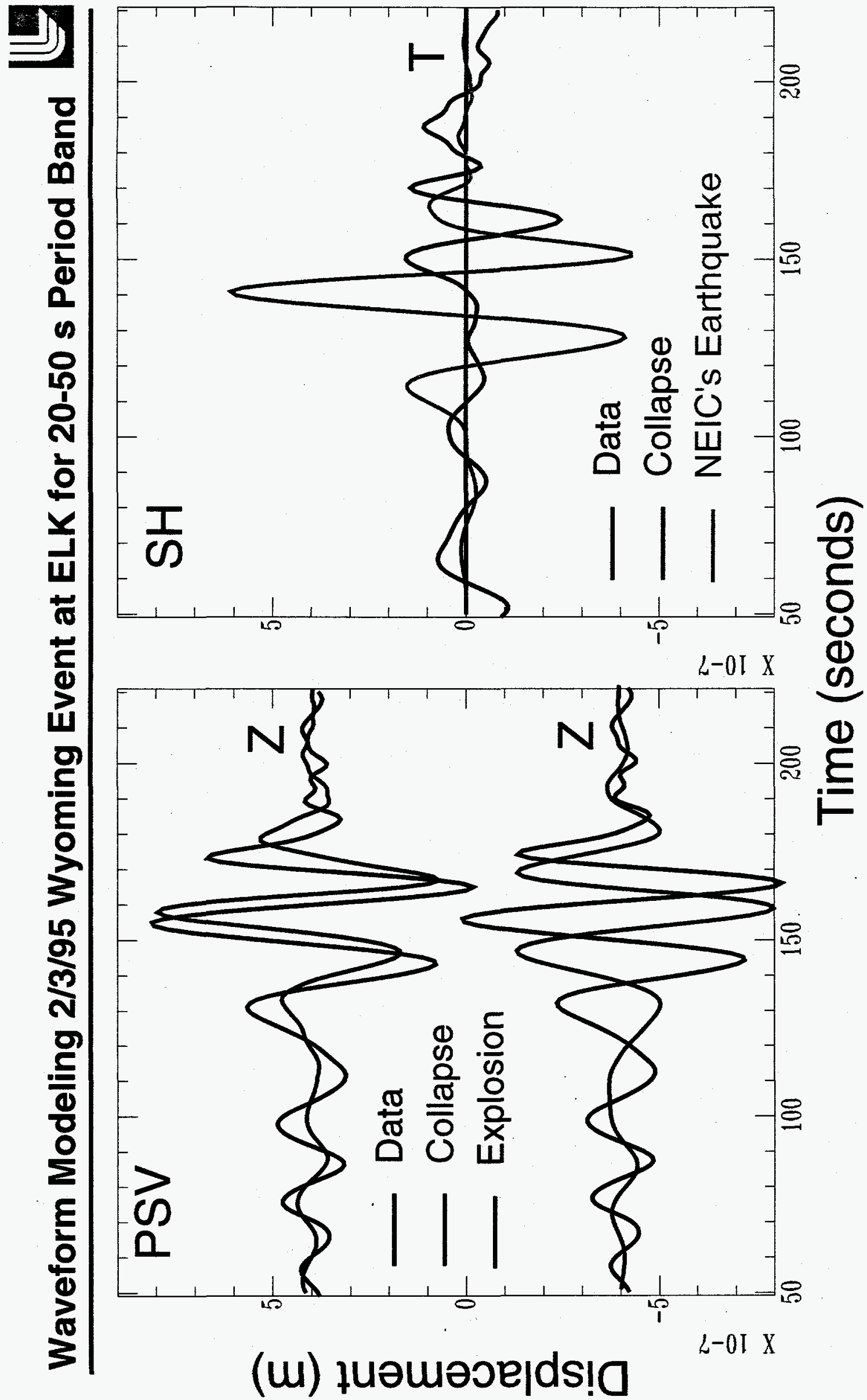

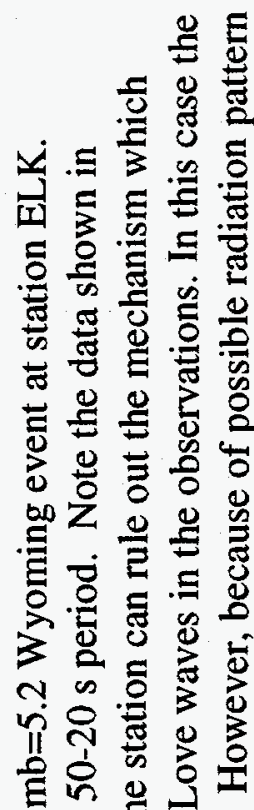

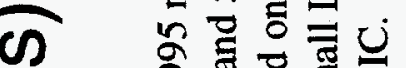

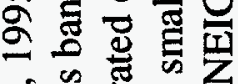
mi 焉焉 응

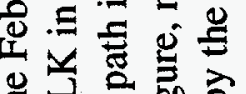

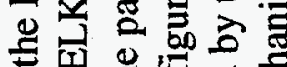

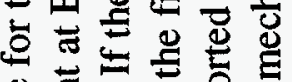
氖苛

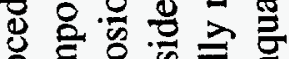
을 完番 os

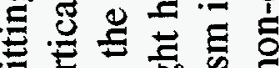
牙 o $>$ 플

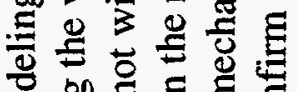

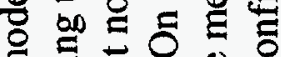
政 E 등 范 응

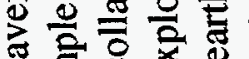
उ

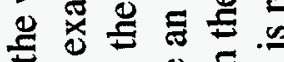

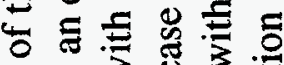
닌 을 总至矛

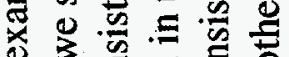
¿ $+\stackrel{2}{2}$ $\checkmark$ 先

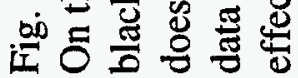




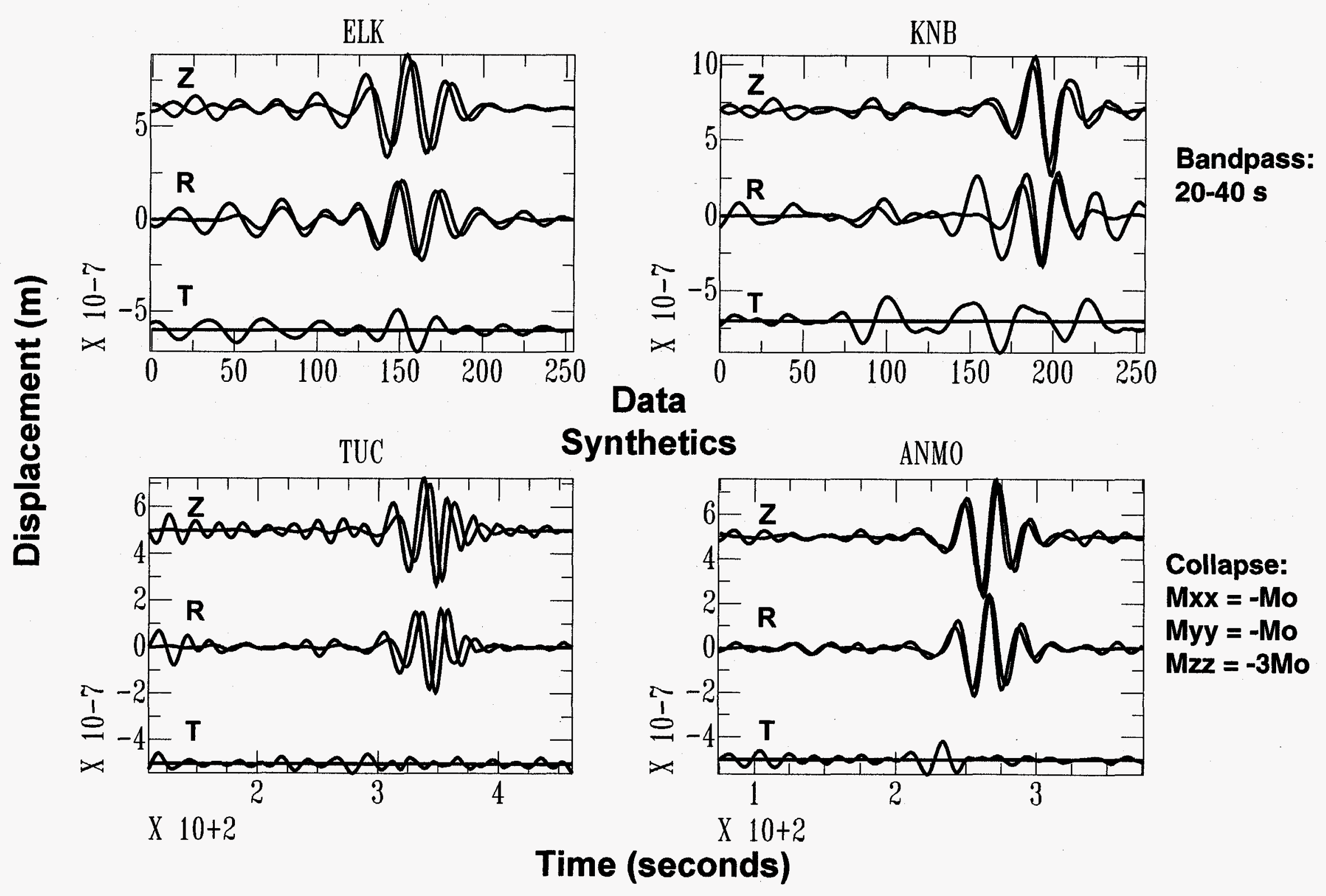

Fig. 5. Waveform modeling at multiple stations with calibrated paths confirms the event was a mine collapse. 
Waveform Modeling: 1/5/95 Urals Event is Consistent with a Collapse

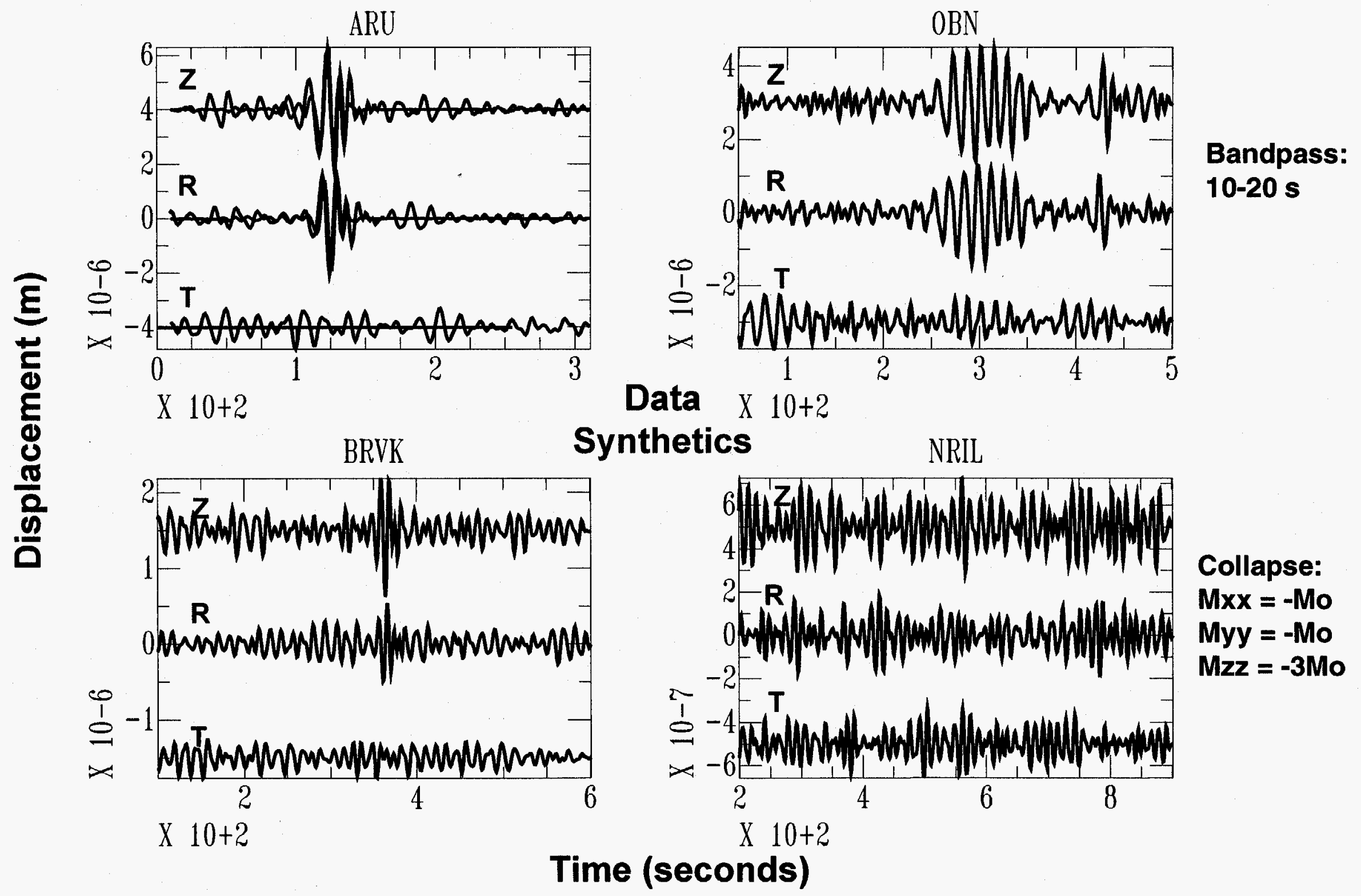

Fig. 6. Waveform modeling at ARU consistent with collapse. Lack of Love waves at other stations points strongly toward pure collapse source. 